\title{
Associations between Paternal Anxiety and Infant Weight Gain
}

\author{
Nobutoshi Nawa ${ }^{1,2, *}$, Angela C. B. Trude ${ }^{3}$, Maureen M. Black ${ }^{3,4}\left(\mathbb{D}\right.$, Lorenzo Richiardi $^{5}\left(\mathbb{D}\right.$ and Pamela J. Surkan ${ }^{6}(\mathbb{D}$ \\ 1 Department of Global Health Promotion, Tokyo Medical and Dental University, Tokyo 113-8519, Japan \\ 2 Department of Medical Education Research and Development, Tokyo Medical and Dental University, \\ Tokyo 113-8519, Japan \\ 3 Department of Pediatrics, School of Medicine, University of Maryland, Baltimore, MD 21201, USA \\ angela.trude@nyu.edu (A.C.B.T.); mblack@som.umaryland.edu (M.M.B.) \\ 4 RTI International, Research Triangle Park, NC 27709, USA \\ 5 Cancer Epidemiology Unit, Department of Medical Sciences, CPO-Piemonte, University of Turin, \\ 10126 Turin, Italy; lorenzo.richiardi@unito.it \\ 6 Department of International Health, Bloomberg School of Public Health, Johns Hopkins University, \\ Baltimore, MD 21205, USA; psurkan@jhu.edu \\ * Correspondence: nawa.ioe@tmd.ac.jp
}

check for updates

Citation: Nawa, N.; Trude, A.C.B.; Black, M.M.; Richiardi, L.; Surkan, P.J Associations between Paternal Anxiety and Infant Weight Gain. Children 2021, 8, 977. https://doi.org/ 10.3390/children8110977

Received: 28 September 2021

Accepted: 25 October 2021

Published: 28 October 202

Publisher's Note: MDPI stays neutral with regard to jurisdictional claims in published maps and institutional affiliations.

Copyright: (c) 2021 by the authors. Licensee MDPI, Basel, Switzerland. This article is an open access article distributed under the terms and conditions of the Creative Commons Attribution (CC BY) license (https:// creativecommons.org/licenses/by/ $4.0 /)$

\begin{abstract}
The aim of this study was to examine the relationship between parental anxiety (fatheronly, mother-only, or both) and infant weight change. We performed a secondary data analysis among 551 children in the Avon Longitudinal Study of Parents and Children, a birth cohort with weight measurements collected prospectively at 4, 8, and 12 months of age. Paternal and maternal anxiety symptoms were based on the eight-item anxiety subscale of the Crown-Crisp Experiential Index. Scores in the top $15 \%$ at 8 weeks postpartum were classified as high anxiety. Generalized Estimating Equations were employed to estimate the joint association between parental anxiety and change in child weight-for-age z-score. Children who had fathers, but not mothers, with anxiety showed a 0.15 (95\% CI: 0.01, 0.29) greater increase in weight-for-age z-score than children with neither parent anxious. This result suggests that paternal anxiety, not maternal anxiety, was associated with increases in child weight gain in the first year of life. Public health practitioners and clinicians should consider the use of robust measures of both maternal and paternal anxiety in the postpartum period, in addition to the suggested screening for postpartum depression. Given the limitations of the study, this study should be considered preliminary and hypothesis generating.
\end{abstract}

Keywords: anxiety; pediatric obesity; longitudinal studies

\section{Introduction}

Rapid weight gain in the first year of life can lead to adverse health consequences, including increased risk for obesity and other chronic diseases [1-3]. Prior studies have linked maternal depression and anxiety to excess infant weight gain [4,5]. Plausible explanations for this association include changes in maternal feeding practices (e.g., restrictive feeding practices, nonresponsive feeding styles, reduced breast-feeding duration) that are known to be associated with excess infant weight gain [6-11]. Although many studies have examined the relation between maternal mental health and infant weight gain $[4,5]$, paternal anxiety has been understudied. Paternal anxiety is estimated to occur in $4.0-16.0 \%$ of fathers prenatally and between $2.5 \%$ and $18.0 \%$ postnatally in several high-income countries [12], suggesting that paternal anxiety may also play an important role in excess infant weight gain.

From a family perspective, anxiety in either parent may influence the other parent's relationship with the child [13]. For example, fathers with anxiety may influence maternal feeding practices associated with excess infant weight gain. Paternal and maternal anxiety are positively correlated with child anxiety $[14,15]$, which in turn may influence children's self-regulation and fussiness during mealtimes [16]. Thus, anxiety in both mothers and 
fathers could be associated with changes in children's weight over time. Parental anxiety may be triggered by multiple factors, including concerns about abnormal infant weight gain, or feeding problems [17]. Since feeding difficulties, which can be caused by, for example, fussiness in infants, may induce anxiety in parents [17], we considered it possible that parental anxiety related to feeding difficulties could be associated with changes in feeding behaviors (e.g., parents changing the frequency and method of feeding) and in turn, related to infant weight gain. However, as we have shown previously, maternal anxiety, regardless of perceived feeding difficulties may also lead to infant weight gain [5]. As the mechanism of the association between parental anxiety and excess infant weight gain may differ depending on the presence or absence of feeding difficulties, we examined whether maternal-reported feeding difficulties modified the association between parental anxiety and excess infant weight gain. Longitudinal designs that assess relations between parental anxiety evaluated prior to infant weight measurements, infant weight gain, and feeding problems are particularly relevant, but rare.

In this study, we analyzed the Avon Longitudinal Study of Parents and Children (ALSPAC) cohort data [18] collected at multiple time points during the first year of life. In the ALSPAC cohort, fathers and mothers reported symptoms of general anxiety using the eight-item subscale of generalized anxiety from the Crown-Crisp Experiential Index prior to the measurement of infant weight gain [19-28]. High anxiety symptoms were defined as the top 15\% (85th percentile or higher) of parents' Crown-Crisp Experimental Index scores at 8 weeks postpartum, and low anxiety symptoms were defined as those below the 85th percentile at 8 weeks postpartum. This cutoff value was based on the prevalence of maternal anxiety before and after childbirth in the UK [29] and has been used previously in studies of maternal and paternal anxiety using ALSPAC data [21-26,30].

The objective of this study was to investigate if parental anxiety (father-only, motheronly, or both) was related to weight change in infancy (defined by change in infant weightfor-age z-scores). A secondary aim was to examine if mother-reported feeding difficulties modified the association between parental anxiety and excess infant weight gain. Given the association between child's sex [31] and the mother's postpartum depression, as well as differences in the child growth depending on child's sex, we also examined whether child's sex modified the association between parental anxiety and excess infant weight gain.

\section{Materials and Methods}

\section{Sample}

We analyzed data from participants in the Children in Focus (CiF) sub-study, which corresponds to $10 \%$ of the ALSPAC cohort, who attended clinics at the University of Bristol. Initially, ALSPAC recruited 14,541 pregnant women in Avon who were expecting to deliver between 1 April 1991 and 31 December 1992. A total of 14,541 pregnant women who were enrolled in the ALSPAC study returned at least one questionnaire or attended a "Children in Focus" clinic by 19 July 1999. Of these initial pregnancies, there were 14,676 fetuses, resulting in 14,062 livebirths and 13,988 children who were alive at 1 year of age [32,33] (the study website contains details of all available data through a fully searchable data dictionary and variable search tool [34]). We excluded infants with major congenital abnormalities, cerebral palsy, and non-singleton births [35]. The CiF group was chosen at random from the final 6 months of ALSPAC births, corresponding to 1432 families who attended at least one clinic visit. We excluded mothers who had moved out of the area, who were lost to follow-up, or who were enrolled in another study of infant development conducted in Avon $[18,36,37]$. Our analysis focused on infant weight change between the median ages of four and 12 months of age. We chose this age group because rapid weight gain during infancy is associated with later child obesity and other chronic diseases [1-3]. While $\mathrm{CiF}$ data were collected at various time intervals between 4 and 61 months of age, we included infants who were weighed during the earlier assessments conducted at the median ages of 4, 8, and 12 months, resulting in an analytical sample of 551 infants. The 
ALSPAC Ethics and Law Committee and the Local Research Ethics Committees approved this study.

\section{Measures}

\subsection{Independent Variable \\ Parental Anxiety Symptoms}

Given that anxiety among mothers and fathers during the perinatal period is common in high-income countries $[12,29,38,39]$, in this study we focused on parental anxiety symptoms. Maternal and paternal anxiety were based on an eight-item subscale of general anxiety from the Crown-Crisp Experiential Index [19-28], reported by mothers and fathers. Examples of items in the subscale include "Do you feel upset for no obvious reason?" and "Do you feel strung-up inside?" Scores range from 0 to 16 with higher scores indicating more symptoms of anxiety. Parents who scored in the top 15\% (85th percentile or higher) on the Crown-Crisp Experimental Index were considered to have high symptoms of anxiety (referred to as having 'high anxiety'). Parents with scores below the 85th percentile were considered to have low symptoms of anxiety (referred to as having "low anxiety"). This cutoff was derived from the prevalence of anxiety among antenatal and postnatal mothers in the UK [29], and has been previously used in research on maternal and paternal anxiety using the ALSPAC data [21-26,30]. Our prior study of the relationship between maternal anxiety and gain in child BMI also used this cutoff [5]. We used data at 8 weeks postpartum for parental anxiety. The 85th percentile value of the Crown-Crisp Experimental Index at 8 weeks postpartum was 5 and 6 points for fathers and mothers, respectively. Maternal and paternal anxiety were dichotomized and analyzed as categorical variables with four categories, i.e., by creating combinations of paternal and maternal anxiety (high anxiety in mothers only, high anxiety in fathers only, high anxiety in both parents, and low anxiety in both parents) for ease of interpretation.

\subsection{Moderator}

Feeding Difficulties at the 6-Month Assessment

Feeding difficulties were assessed by asking mothers: "Do you feel you have ever had difficulties feeding your baby?" at the 6-month assessment. Response categories include "no difficulty", "some difficulty", and "yes, great difficulty". This scale has been used in previous ALSPAC studies $[40,41]$. We dichotomized this variable based on previous literature [40,41] and defined a priori: "no difficulty" (coded as 0), and "with difficulty" (coded as 1), which combined some difficulty and great difficulty responses. The prevalence of feeding difficulties at 6 months was $32.3 \%$.

\subsection{Covariates}

Covariates were maternal age, pre-pregnancy self-reported weight and height, education level, parity and race/ethnicity, paternal age, education level, and marital status (all assessed during pregnancy), and child birthweight, child gestational age, and sex (all assessed at birth). Feeding method (bottle feeding, breastfeeding, both bottle feeding and breastfeeding, and other) was assessed at 4 weeks postpartum. Variables were chosen based on associations reported previously [5,42]. Maternal age, pre-pregnancy self-reported weight and height, parity, paternal age, child birthweight, and child gestational age were used as continuous variables, while maternal education level (lower than O-level, O-level, A-level, degree), race/ethnicity (other race/ethnicity, White), paternal education level (lower than O-level, O-level, A-level, degree), marital status ('single' included never married, widowed divorced and separated; 'married' included both first or later marriages), and child sex (male, female) were treated as categorical variables. In terms of parental education level, A level or 'advanced level' is the level of a post-compulsory education usually taken at age 18. O level or 'ordinary level' is at the end of compulsory education usually taken at age $16[43,44]$. We did not have information on whether mothers or fathers were living with their children during the study period. It is also possible that some of the 
partners who responded to the partner questionnaire from which we extracted information on paternal anxiety were not the biological fathers of the children. Therefore, we were not able to take these factors into account in the analysis.

\subsection{Dependent Variable \\ Child Weight}

Child weight was measured in clinics at the University of Bristol to the nearest $0.1 \mathrm{~kg}$ when children (weighed wearing only underwear) were median ages of 4 (min: 3.5, max: 4.8), 8 (min: 7.4, max: 9.5), and 12 (min: 11.8, max: 13.9) months. Measurements were taken using a Fereday $100 \mathrm{~kg}$ combined scale at 4 months, a Soenhle scale or a Seca 724 scale at 8 months, and a Seca 724 or a Seca 835 Scale at 12 months. Considering that the data were collected in the UK in the 1990s, we used the UK 1990 growth reference curves [45,46] to convert data to weight-for-age z-scores.

\section{Statistical Analyses}

All statistical analyses were conducted using R, version 3.4.3. We used Generalized Estimating Equations (GEE) with the "gee" package, version 4.13-19 to estimate associations between parental anxiety and child change in weight-for-age z-score from the first time point (median age of 4 months) to the third time point (median age of 12 months) by accounting for within-individual associations between repeated measures from the same child [47]. We included an interaction term between parental anxiety and child age in the model to assess whether child weight-for-age z-score trajectories varied by parental anxiety. We centered child age at 4 months and scaled so that a one-unit change in age could be interpreted as a change over 4 months. We also explored heterogeneity by child sex. Since results did not differ by sex, child sex was included as a covariate.

We investigated if the association between parental anxiety (at 8 weeks postpartum) and infant weight gain from 8 to 12 months was modified by feeding difficulties when children were 6 months old using GEE analyses. We included an interaction term between combinations of paternal and maternal anxiety (coded as maternal-only high anxiety, paternal-only high anxiety, high anxiety in both parents, low anxiety in both parents (reference group)) and feeding difficulties in the model. Age was also included in a threeway interaction term to assess whether the rate of change in child weight-for-age z-scores varied by child parental anxiety status with or without child feeding difficulties.

\section{Missing Data}

Missing values ranged from $0.4 \%$ for birthweight to $29.9 \%$ for paternal age. To handle missing values on covariates, we used multiple imputation and created 50 imputed datasets using the "mice" package, version 2.46.0 [48]. The results of analyses using all the imputed datasets were combined using Rubin's rules for multiple imputation [49].

\section{Results}

As shown in Table 1, mean ages of mothers and fathers were 28.5 years (SD: 4.5$)$ and 31.5 years (SD: 5.5$)$, respectively. Most mothers were White, and $78.9 \%$ of mothers were married. The prevalence of high anxiety was $21.2 \%$ among mothers and $14.2 \%$ among fathers at 8 weeks. In total, $64.9 \%$ of families reported low anxiety in both parents, while $7.2 \%$ of families reported high anxiety in both parents. One third of the mothers reported feeding difficulties when the child was 6 months old. 
Table 1. Characteristics of study participants (total $n=551$ ).

\begin{tabular}{|c|c|c|}
\hline Variable & $n$ & $\%$ \\
\hline \multicolumn{3}{|l|}{ Parental characteristics } \\
\hline \multicolumn{3}{|l|}{ Maternal education $^{\mathrm{a}}$} \\
\hline Lower than O-level & 105 & 19.1 \\
\hline O-level & 198 & 35.9 \\
\hline A-level & 150 & 27.2 \\
\hline Degree & 62 & 11.3 \\
\hline Missing & 36 & 6.5 \\
\hline \multicolumn{3}{|l|}{ Paternal education ${ }^{\mathrm{a}}$} \\
\hline Lower than O-level & 91 & 16.5 \\
\hline O-level & 105 & 19.1 \\
\hline A-level & 151 & 27.4 \\
\hline Degree & 89 & 16.2 \\
\hline Missing & 115 & 20.9 \\
\hline \multicolumn{3}{|l|}{ Maternal race/ethnicity } \\
\hline Other than White & 8 & 1.5 \\
\hline White & 527 & 95.6 \\
\hline Missing & 16 & 2.9 \\
\hline \multicolumn{3}{|l|}{$\begin{array}{l}\text { High maternal anxiety } \\
\text { at } 8 \text { weeks postpartum }\end{array}$} \\
\hline Yes & 117 & 21.2 \\
\hline No & 411 & 74.6 \\
\hline Missing & 23 & 4.2 \\
\hline \multicolumn{3}{|l|}{$\begin{array}{l}\text { High paternal anxiety } \\
\text { at } 8 \text { weeks postpartum }\end{array}$} \\
\hline Yes & 78 & 14.2 \\
\hline No & 339 & 61.5 \\
\hline Missing & 134 & 24.3 \\
\hline \multicolumn{3}{|l|}{ Marital status } \\
\hline Single & 105 & 19.1 \\
\hline Married & 435 & 78.9 \\
\hline Missing & 11 & 2.0 \\
\hline \multicolumn{3}{|l|}{ Feeding method at 4 weeks postpartum } \\
\hline Breastfeeding & 257 & 46.6 \\
\hline Bottle feeding & 205 & 37.2 \\
\hline Breastfeeding and bottle feeding & 71 & 12.9 \\
\hline Other & 4 & 0.7 \\
\hline Missing & 14 & 2.5 \\
\hline \multicolumn{3}{|l|}{ Feeding difficulties at the age of 6 months } \\
\hline Yes & 178 & 32.3 \\
\hline No & 350 & 63.5 \\
\hline \multirow[t]{2}{*}{ Missing } & 23 & 4.2 \\
\hline & Mean & SD \\
\hline Maternal age (years) & 28.5 & 4.5 \\
\hline Paternal age (years) & 31.5 & 5.5 \\
\hline Maternal pre-pregnancy weight $(\mathrm{kg})$ & 63.2 & 11.4 \\
\hline Maternal height $(\mathrm{cm})$ & 164.4 & 6.2 \\
\hline $\begin{array}{l}\text { Maternal pre-pregnancy body } \\
\text { mass index }\left(\mathrm{kg} / \mathrm{m}^{2}\right)\end{array}$ & 23.5 & 4.2 \\
\hline Parity & 0.8 & 1.0 \\
\hline
\end{tabular}


Table 1. Cont.

\begin{tabular}{|c|c|c|}
\hline Variable & $n$ & $\%$ \\
\hline & $n$ & $\%$ \\
\hline \multicolumn{3}{|l|}{ Sex } \\
\hline Male & 284 & 51.5 \\
\hline Female & 267 & 48.5 \\
\hline Missing & 0 & 0 \\
\hline \multicolumn{3}{|l|}{ Low birthweight } \\
\hline Yes & 17 & 3.1 \\
\hline No & 532 & 96.6 \\
\hline Missing & 2 & 0.4 \\
\hline \multicolumn{3}{|l|}{ Preterm birth } \\
\hline Yes & 18 & 3.3 \\
\hline No & 533 & 96.7 \\
\hline \multirow[t]{2}{*}{ Missing } & 0 & 0 \\
\hline & Mean & SD \\
\hline Birthweight (g) & 3437 & 491 \\
\hline Gestational age (weeks) & 39.5 & 1.5 \\
\hline Child weight-for-age $z$-score at 4 months ${ }^{b}$ & -0.19 & 0.92 \\
\hline Child weight-for-age z-score at 8 months ${ }^{b}$ & 0.00 & 1.00 \\
\hline Child weight-for-age z-score at 12 months ${ }^{b}$ & 0.09 & 0.98 \\
\hline $\begin{array}{l}\text { Child weight-for-age z-score change from } 4 \text { to } 8 \\
\text { months a }\end{array}$ & 0.19 & 0.61 \\
\hline $\begin{array}{l}\text { Child weight-for-age z-score change from } 8 \text { to } \\
12 \text { months }^{\text {a }}\end{array}$ & 0.09 & 0.46 \\
\hline
\end{tabular}

Table $\mathrm{S} 1$ shows raw data (without fitting a regression model) of the mean child weightfor-age z-score measured at the median ages of 4, 8, and 12 months by parental anxiety in the unimputed dataset. The weight-for-age z-score of children who had mothers (but not fathers) with high anxiety increased from -0.59 at the age of 4 months to -0.23 at the age of 12 months, whereas the weight-for-age z-score of children of fathers (but not mothers) with high anxiety increased from -0.13 to 0.23 over this same time period.

Table 2 shows the regression model-derived associations of paternal and maternal anxiety with change in child weight-for-age z-score from the first time point (median age 4 months) to the third time point (median age of 12 months). In the imputed samples, $7.2 \%$ of children had both parents with high anxiety. After covariate adjustment, children with parents for whom only fathers had high anxiety (i.e., the mothers did not have high anxiety) showed greater increases in weight-for-age z-score for each 4-month increase in child age ( $\beta=0.15,95 \%$ CI: $0.01,0.29$, i.e., the coefficient for the child age ${ }^{*}$ high anxiety interaction in fathers only) compared to children for whom both parents were in the low anxiety group.

Table 2. Categorical profiles of paternal and maternal anxiety with change in child weight-for-age z-score from the first time point (median age of 4 months) to the third time point (median age of 12 months) in the imputed dataset using GEE ${ }^{\text {a }}$.

\begin{tabular}{|c|c|c|c|}
\hline & & Crude & Adjusted $^{b}$ \\
\hline & $\%$ & $\beta(95 \% \mathrm{CI})$ & $\beta(95 \% \mathrm{CI})$ \\
\hline Child age & & $\begin{array}{c}0.07 \\
(0.03,0.11)^{\dagger}\end{array}$ & $\begin{array}{c}0.05 \\
(0.006,0.09)^{\dagger}\end{array}$ \\
\hline $\begin{array}{l}\text { Parental anxiety } \\
\text { Low anxiety in fathers and mothers }\end{array}$ & $64.9 \%$ & 0.00 (Reference) & 0.00 (Reference) \\
\hline
\end{tabular}


Table 2. Cont.

\begin{tabular}{|c|c|c|c|}
\hline & & Crude & Adjusted $^{b}$ \\
\hline & $\%$ & $\beta(95 \% \mathrm{CI})$ & $\beta(95 \% \mathrm{CI})$ \\
\hline High anxiety in fathers only & $12.8 \%$ & $\begin{array}{c}-0.06 \\
(-0.32,0.21)\end{array}$ & $\begin{array}{c}-0.11 \\
(-0.36,0.15)\end{array}$ \\
\hline High anxiety in mothers only & $15.1 \%$ & $\begin{array}{c}-0.32 \\
(-0.57,-0.07)^{\dagger}\end{array}$ & $\begin{array}{c}-0.28 \\
(-0.52,-0.04)^{\dagger}\end{array}$ \\
\hline High anxiety in both mothers and fathers & $7.2 \%$ & $\begin{array}{c}0.26 \\
(-0.08,0.60)\end{array}$ & $\begin{array}{c}0.20 \\
(-0.13,0.53)\end{array}$ \\
\hline Child age * Low anxiety in fathers and mothers & & $\begin{array}{c}0.00 \\
\text { (Reference) }\end{array}$ & $\begin{array}{c}0.00 \\
\text { (Reference) }\end{array}$ \\
\hline Child age ${ }^{*}$ High anxiety in fathers only & & $\begin{array}{c}0.12 \\
(0.01,0.24)^{+}\end{array}$ & $\begin{array}{c}0.15 \\
(0.01,0.29)^{\dagger}\end{array}$ \\
\hline Child age * High anxiety in mothers only & & $\begin{array}{c}0.07 \\
(-0.03,0.17)\end{array}$ & $\begin{array}{c}0.08 \\
(-0.05,0.20)\end{array}$ \\
\hline Child age ${ }^{*}$ High anxiety in both mothers and fathers & & $\begin{array}{c}-0.004 \\
(-0.12,0.11)\end{array}$ & $\begin{array}{c}0.004 \\
(-0.13,0.14)\end{array}$ \\
\hline
\end{tabular}

${ }^{a}$ We centered age at 4 months and scaled age so that the effect of a one-unit change in age can be interpreted as the effect of a 4-month increase in age. ${ }^{b}$ Adjusted for maternal age, pre-pregnancy weight, height, education, parity, race/ethnicity, marital status, paternal education, age, child birthweight, gestational age, sex, and feeding method. Child age*parental anxiety refers to the interaction term between child age and parental anxiety. ${ }^{\dagger} p<0.05$.

Table 3 shows the associations of paternal and maternal anxiety with change in child weight-for-age $z$-score from the second time point (median age 8 months) to the third time point (median age 12 months), stratified by feeding difficulties when children were 6 months old. Among children with feeding difficulties, high paternal anxiety was associated with a $0.24(95 \%$ CI: $0.02,0.46)$ greater increase in weight-for-age $\mathrm{z}$-score compared to children whose fathers and mothers had low anxiety. The $p$-value for the three-way interaction term (child feeding difficulties by paternal anxiety by child age) was 0.36 .

Table 3. Categorical profiles of paternal and maternal anxiety with change in child weight-for-age z-score from the second time point (median age of 8 months) to the third time point (median age of 12 months) in the imputed dataset, stratified by feeding difficulties with GEE ${ }^{\text {a }}$ (because the outcome has two timepoints).

\begin{tabular}{|c|c|c|}
\hline & Crude & Adjusted $^{b}$ \\
\hline & $\beta(95 \% C I)$ & $\beta(95 \% C I)$ \\
\hline \multicolumn{3}{|c|}{$\begin{array}{l}\text { Child weight-for-age z-score change from } 8 \text { to } 12 \text { months } \\
\text { Child feeding difficulty }\end{array}$} \\
\hline Child age & $0.05(-0.02,0.12)$ & $0.05(-0.02,0.12)$ \\
\hline \multicolumn{3}{|l|}{ Parental Anxiety } \\
\hline Low anxiety in fathers and mothers & 0.00 (Reference) & 0.00 (Reference) \\
\hline High anxiety in fathers only & $-0.38(-0.84,0.08)$ & $-0.35(-0.90,0.19)$ \\
\hline High anxiety in mothers only & $-0.33(-0.74,0.07)$ & $-0.22(-0.59,0.15)$ \\
\hline High anxiety in both mothers and fathers & $0.20(-0.46,0.86)$ & $0.02(-0.52,0.56)$ \\
\hline $\begin{array}{l}\text { Child age * Low anxiety } \\
\text { in fathers and mothers }\end{array}$ & 0.00 (Reference) & 0.00 (Reference) \\
\hline $\begin{array}{l}\text { Child age }{ }^{*} \text { High anxiety } \\
\text { in fathers only }\end{array}$ & $0.24(0.02,0.46)^{\dagger}$ & $0.24(0.02,0.46)^{\dagger}$ \\
\hline $\begin{array}{l}\text { Child age }{ }^{*} \text { High anxiety } \\
\text { in mothers only }\end{array}$ & $0.08(-0.08,0.24)$ & $0.08(-0.08,0.24)$ \\
\hline $\begin{array}{l}\text { Child age }{ }^{*} \text { High anxiety } \\
\text { in both mothers and fathers }\end{array}$ & $0.04(-0.16,0.24)$ & $0.04(-0.16,0.24)$ \\
\hline
\end{tabular}


Table 3. Cont.

\begin{tabular}{|c|c|c|}
\hline & Crude & Adjusted $^{b}$ \\
\hline & $\beta(95 \% \mathrm{CI})$ & $\beta(95 \% C I)$ \\
\hline \multicolumn{3}{|c|}{$\begin{array}{c}\text { Child weight-for-age z-score change from } 8 \text { to } 12 \text { months } \\
\text { No child feeding difficulty }\end{array}$} \\
\hline Child age & $0.05(-0.0002,0.11)$ & $0.05(0.0003,0.11)^{\dagger}$ \\
\hline \multicolumn{3}{|l|}{ Parental Anxiety } \\
\hline Low anxiety in fathers and mothers & 0.00 (Reference) & 0.00 (Reference) \\
\hline High anxiety in fathers only & $0.13(-0.22,0.48)$ & $0.09(-0.22,0.41)$ \\
\hline High anxiety in mothers only & $-0.16(-0.53,0.21)$ & $-0.15(-0.50,0.19)$ \\
\hline High anxiety in both mothers and fathers & $0.26(-0.19,0.71)$ & $0.23(-0.20,0.66)$ \\
\hline $\begin{array}{l}\text { Child age * Low anxiety } \\
\text { in fathers and mothers }\end{array}$ & 0.00 (Reference) & 0.00 (Reference) \\
\hline $\begin{array}{l}\text { Child age * High anxiety } \\
\text { in fathers only }\end{array}$ & $0.10(-0.08,0.29)$ & $0.10(-0.08,0.28)$ \\
\hline $\begin{array}{l}\text { Child age * High anxiety } \\
\text { in mothers only }\end{array}$ & $0.08(-0.11,0.27)$ & $0.08(-0.11,0.27)$ \\
\hline $\begin{array}{l}\text { Child age }{ }^{*} \text { High anxiety } \\
\text { in both mothers and fathers }\end{array}$ & $-0.02(-0.20,0.16)$ & $-0.02(-0.20,0.16)$ \\
\hline
\end{tabular}

The $p$-value for the interaction term among child feeding difficulty, high anxiety in fathers and child age is $0.36 .{ }^{a}$ We centered age at 4 months and scaled age so that the effect of a one-unit change in age can be interpreted as the effect of a 4 month increase in age. ${ }^{b}$ Adjusted for maternal age, pre-pregnancy weight, height, education, parity, race/ethnicity, marital status, paternal education, age, child birthweight, gestational age, sex, and feeding method. Child age* parental anxiety refers to the interaction term between child age and parental anxiety. † $p<0.05$.

\section{Discussion}

In this study, we found that children who had fathers but not mothers with high anxiety showed a clinically significant increase in weight-for-age z-score over 8 months, compared to children with neither fathers nor mothers with high anxiety. This pattern was replicated among children with feeding difficulties, where high paternal anxiety was associated with a clinically significant increase in weight-for-age z-score compared to children whose fathers and mothers had low anxiety.

Maternal and paternal anxiety during the perinatal period is common in high-income countries $[12,29,38,39]$. A prior study found that pre- and post-natal maternal anxiety was associated with an increase in child BMI at age 2 years (25-31 months of age), with no consideration of paternal anxiety [5]. To date, we are not aware of any studies that have assessed the relationship between paternal anxiety and infant weight gain. Given the relative paucity of existing data on the influence of paternal (relative to maternal) anxiety, these findings add to the literature by highlighting the potential importance of paternal anxiety on infant development.

A possible explanation for the finding that high anxiety in fathers but not in mothers was associated with increases in child weight-for-age z-score may be differences in the sex-specific manifestations of anxiety [50]. For example, qualitative studies on fathers have reported difficulties in balancing work and family life (especially sleeping and feeding patterns) in the presence of psychosocial distress [51,52]. In a qualitative study in the UK, fathers attributed higher levels of anxiety to greater financial pressure after becoming parents [52], thus potentially influencing household food security and quality of available food that could lead to child weight gain. We lacked information on unemployment and food security and could not study this issue further. Furthermore, the underlying causes of anxiety may be different for mothers and fathers. We did not find a joint effect of maternal and paternal anxiety on infant weight gain trajectory, possibly due to the low prevalence of households with high anxiety among both mothers and fathers (7.1\%). It is possible that paternal mental health symptoms during the perinatal period may pose negative 
consequences for the whole family including family relationships as well as the health of their spouses and children [53].

Paternal mental health problems can lead to marital conflicts that can negatively impact the entire family [54]. In most countries and cultures, fathers are becoming more involved in child rearing than previously [54]. Given that paternal psychological wellbeing may influence fathers' parenting behaviors and the family as a whole, paternal wellbeing may play a significant role on children's weight, growth, and development.

We also assessed whether infant feeding difficulties modified the association between high paternal anxiety and infant weight gain, given the association between paternal anxiety and children's self-regulation and fussiness during mealtimes [14-16]. Our results suggest that mother-reported feeding difficulties did not modify the association. This is perhaps partially explained by the use of a single-item feeding difficulties measure. In addition, feeding problems are relatively common at 6 months, when infants transition from a liquid diet of breast milk or formula via breast or bottle to a complementary diet of semi-solid foods that are often spoon-fed or self-fed [55]. Parents may have anticipated a transition and had strategies to deal with the feeding problems at 6 months [55]. Future studies should use robust and validated methods to evaluate feeding difficulties, from the perspectives of both parents.

Our findings have clinical implications. In this study, we found that children who had fathers but not mothers with high anxiety showed a clinically significant increase in weight-for-age z-score over 8 months, compared to children with neither fathers nor mothers with high anxiety. If this increase in weight gain continues over 2 years, it would translate to a weight gain of about $0.90 \mathrm{SD}$, exceeding the criterion for rapid weight gain of 0.67 SD over 2 years [56-58]. Guidelines from the National Institute for Health and Care Excellence (NICE) in the UK recommends screening for maternal postpartum depression and anxiety and calls attention to the importance of considering the mental health needs of fathers or partners [29]. The American Academy of Pediatrics recently recommended routine screening for maternal postpartum depression at well-child visits at 1, 2, 4, and 6 months of age [59]. Their statement also recommends screening the partner for depression at the 6-month visit using the Edinburgh Postpartum Depression Scale (EPDS) $[59,60]$. Screening and referrals for parental mental health may protect children from the negative consequences of exposure to mental illness in the home and associated adverse current and later health consequences [59,61]. However, the EPDS was not designed to measure anxiety and includes only three anxiety-specific items [60]. Given the association that we observed between high paternal anxiety and infant weight gain as well as other research on paternal anxiety and child development $[15,54,62]$, clinicians should consider screening both mothers and fathers for anxiety in the postpartum period (for possible intervention if identified) [63,64], in addition to screening for depression at 6-months postpartum. Interventions may include digital mental health using web-based information and communication technologies that have been reported to be effective in a recent systematic review and meta-analysis [63].

Study strengths include father-reported information on fathers' emotional state, which has been largely neglected in the literature, adding to the value of this investigation. Another major advantage is the use of the relatively large longitudinal ALSPAC dataset. As parental anxiety could be triggered by concerns about abnormal weight and/or growth of the child, a longitudinal design is needed to assess the relation between parental anxiety evaluated prior to infant weight measurements and infant weight gain. By analyzing data from the longitudinal ALSPAC dataset, we found that paternal anxiety was associated with increases in infant weight gain in the first year of life, to a degree that exceeded the definition of rapid weight gain.

Our study has several limitations. First, we did not have information on whether mothers and fathers were still married or co-habitating over the course of data collection (from child age 4 to 12 months). It is also possible that not all the participants who responded to the partner questionnaire (from which we extracted information on paternal 
anxiety) were biological fathers of the child. Second, anxiety was based on a brief symptom checklist, rather than a diagnostic interview. Third, the choice of 85th percentile cutoff for paternal anxiety was based on use of this cutoff to define anxiety in prior research [28], including an ALSPAC study of paternal anxiety [30]. In the absence of established cutoffs for paternal anxiety, future validation studies should establish appropriate cutoffs to be used. Fourth, we did not have information on the content of the milk that was being bottle fed (breast milk vs. formula). Fifth, in order to calculate the error in the measurement of infant body weight, it is necessary to take multiple measurements, but since no such data were collected, measurement error cannot be calculated and is unknown. Sixth, the mechanism of the association between paternal anxiety and infant weight gain is not yet known. Future research could examine whether fathers with anxiety increase their involvement with bottle feeding due to concern over poor weight gain, thereby increasing the risk for excess infant weight gain. Future research should also consider children's behavioral and health factors that may influence feeding. Finally, ALSPAC is a valuable longitudinal data set that measures anxiety in both fathers and mothers as well as child weight over time using objective measures. However, the cohort represents a predominantly homogeneous population of White parents in Britain in the 1990s. Compared to the 1990s, society has changed, including changes in family dynamics (e.g., increases in fathers' involvement with infant care, greater proportions of fathers who take paternity leave during the infant's first year) and changes in the sources of parental anxiety (e.g., social media, smart phones). In addition, the stratified analysis by feeding difficulties used a three-way interaction term, which has low statistical power. Therefore, this study should be considered hypothesis-generating and call attention to the potential role of paternal anxiety in current times. Future studies with larger sample sizes using WHO standards to convert data to weight-for-age z-scores and more recent samples are needed to confirm if these findings are generalizable to other and contemporary populations. Studies are also warranted to determine if paternal anxiety in the early postpartum period continues to be associated with increased weight gain over time. Given these limitations, the results of this study should be considered preliminary.

\section{Conclusions}

In conclusion, we found that infants who had fathers but not mothers with high anxiety showed greater increases in weight-for-age z-score than infants with both parents reporting low anxiety. Additional research is needed to examine the mechanisms driving the association. Given the positive association between paternal anxiety and children's weight gain trajectory, future research and clinical work should assess fathers' psychological wellbeing and longitudinal impact on children's health and development.

Supplementary Materials: The following are available online at https:/ /www.mdpi.com/article/10 .3390/children8110977/s1.

Author Contributions: N.N. analyzed data, interpreted the results, and drafted, reviewed and revised manuscript. A.C.B.T. contributed to the conceptualization and the design of the study, interpretation of the data, and helped draft, review, and revise the manuscript. M.M.B., L.R. and P.J.S. provided contributions to the conceptualization and the design of the study, interpretation of the data, and made revisions to the draft and final versions of the manuscript. All authors have read and agreed to the published version of the manuscript.

Funding: The UK Medical Research Council and the Wellcome Trust (Grant ref: 217065/Z/19/Z) and the University of Bristol provide core support for ALSPAC. This study was supported by Grants-inAid for Scientific Research from the Japan Society for the Promotion of Science (JSPS KAKENHI Grant Number 19K20109). This publication is the work of the authors, who will serve as guarantors for the contents of this paper. A comprehensive list of grants funding is available on the ALSPAC website (http:/ / www.bristol.ac.uk/alspac/external/documents/grant-acknowledgements.pdf, [accessed 28 September 2021]). 
Institutional Review Board Statement: This study was approved by the ALSPAC Ethics and Law Committee and the Local Research Ethics Committees (http:/ /www.bristol.ac.uk/media-library/ sites/alspac/documents/governance/Research\%20Ethics\%20Committee\%20approval\%20references. pdf, [accessed 28 September 2021]).

Informed Consent Statement: In this study we conducted a secondary data analysis of anonymized data. Thus, the Informed Consent Statement does not apply to this study.

Data Availability Statement: The data used in this study is third party data and will be available from the ALSPAC Executive Committee (alspac-exec@bristol.ac.uk) upon request.

Acknowledgments: We would like to thank all the families who participated in this study and to the midwives who helped recruit them. We are also grateful to the entire ALSPAC team, including interviewers, computer and laboratory technicians, clerks, researchers, volunteers, managers, receptionists, and nurses.

Conflicts of Interest: The authors have no conflict of interest to disclose.

\section{References}

1. Dennison, B.A.; Edmunds, L.S.; Stratton, H.H.; Pruzek, R.M. Rapid infant weight gain predicts childhood overweight. Obesity 2006, 14, 491-499. [CrossRef]

2. Belfort, M.B.; Rifas-Shiman, S.L.; Rich-Edwards, J.; Kleinman, K.P.; Gillman, M.W. Size at birth, infant growth, and blood pressure at three years of age. J. Pediatr. 2007, 151, 670-674. [CrossRef] [PubMed]

3. Taveras, E.M.; Rifas-Shiman, S.L.; Belfort, M.B.; Kleinman, K.P.; Oken, E.; Gillman, M.W. Weight status in the first 6 months of life and obesity at 3 years of age. Pediatrics 2009, 123, 1177-1183. [CrossRef]

4. Lampard, A.M.; Franckle, R.L.; Davison, K.K. Maternal depression and childhood obesity: A systematic review. Prev. Med. 2014, 59, 60-67. [CrossRef] [PubMed]

5. Nawa, N.; Black, M.M.; Araya, R.; Richiardi, L.; Surkan, P.J. Pre- and post-natal maternal anxiety and early childhood weight gain. J. Affect. Disord. 2019, 257, 136-142. [CrossRef] [PubMed]

6. Farrow, C.V.; Blissett, J.M. Is maternal psychopathology related to obesigenic feeding practices at 1 year? Obes. Res. 2005, 13, 1999-2005. [CrossRef]

7. Hurley, K.M.; Black, M.M.; Papas, M.A.; Caulfield, L.E. Maternal symptoms of stress, depression, and anxiety are related to nonresponsive feeding styles in a statewide sample of WIC participants. J. Nutr. 2008, 138, 799-805. [CrossRef]

8. Fallon, V.; Groves, R.; Halford, J.C.; Bennett, K.M.; Harrold, J.A. Postpartum Anxiety and Infant-Feeding Outcomes. J. Hum. Lact. 2016, 32, 740-758. [CrossRef]

9. Hurley, K.M.; Black, M.M.; Merry, B.C.; Caulfield, L.E. Maternal mental health and infant dietary patterns in a statewide sample of Maryland WIC participants. Matern. Child Nutr. 2015, 11, 229-239. [CrossRef]

10. Paul, I.M.; Downs, D.S.; Schaefer, E.W.; Beiler, J.S.; Weisman, C.S. Postpartum anxiety and maternal-infant health outcomes. Pediatrics 2013, 131, e1218-e1224. [CrossRef]

11. Spill, M.K.; Callahan, E.H.; Shapiro, M.J.; Spahn, J.M.; Wong, Y.P.; Benjamin-Neelon, S.E.; Birch, L.; Black, M.M.; Cook, J.T.; Faith, M.S.; et al. Caregiver feeding practices and child weight outcomes: A systematic review. Am. J. Clin. Nutr. 2019, 109, 990S-1002S. [CrossRef]

12. Leach, L.S.; Poyser, C.; Cooklin, A.R.; Giallo, R. Prevalence and course of anxiety disorders (and symptom levels) in men across the perinatal period: A systematic review. J. Affect. Disord. 2016, 190, 675-686. [CrossRef] [PubMed]

13. Bögels, S.; Phares, V. Fathers' role in the etiology, prevention and treatment of child anxiety: A review and new model. Clin. Psychol. Rev. 2008, 28, 539-558. [CrossRef] [PubMed]

14. O'Donnell, K.J.; Glover, V.; Barker, E.D.; O'Connor, T.G. The persisting effect of maternal mood in pregnancy on childhood psychopathology. Dev. Psychopathol. 2014, 26, 393-403. [CrossRef] [PubMed]

15. Möller, E.L.; Majdandžić, M.; Bögels, S.M. Parental anxiety, parenting behavior, and infant anxiety: Differential associations for fathers and mothers. J. Child Fam. Stud. 2015, 24, 2626-2637. [CrossRef]

16. Epstein, L.H.; Wisniewski, L.; Weng, R. Child and Parent Psychological Problems Influence Child Weight Control. Obes. Res. 1994, 2, 509-515. [CrossRef] [PubMed]

17. Daniels, L.A. Feeding Practices and Parenting: A Pathway to Child Health and Family Happiness. Ann. Nutr. Metab. 2019, 74, 29-42. [CrossRef] [PubMed]

18. University of Bristol. Avon Longitudinal Study of Parents and Children. Cohort Profile. Available online: http://www.bristol.ac. uk/alspac/researchers/cohort-profile/ (accessed on 19 April 2018).

19. Crown, S.; Crisp, A.H. A short clinical diagnostic self-rating scale for psychoneurotic patients. The Middlesex Hospital Questionnaire (M.H.Q.). Br. J. Psychiatry 1966, 112, 917-923. [CrossRef]

20. Birtchnell, J.; Evans, C.; Kennard, J. The total score of the Crown-Crisp Experiential Index: A useful and valid measure of psychoneurotic pathology. Br. J. Med. Psychol. 1988, 61, 255-266. [CrossRef] [PubMed] 
21. O'Connor, T.G.; Heron, J.; Golding, J.; Beveridge, M.; Glover, V. Maternal antenatal anxiety and children's behavioural/emotional problems at 4 years. Report from the Avon Longitudinal Study of Parents and Children. Br. J. Psychiatry 2002, 180, 502-508. [CrossRef]

22. Vaz Jdos, S.; Kac, G.; Emmett, P.; Davis, J.M.; Golding, J.; Hibbeln, J.R. Dietary patterns, n-3 fatty acids intake from seafood and high levels of anxiety symptoms during pregnancy: Findings from the Avon Longitudinal Study of Parents and Children. PLoS ONE 2013, 8, e67671. [CrossRef]

23. Blackmore, E.R.; Cote-Arsenault, D.; Tang, W.; Glover, V.; Evans, J.; Golding, J.; O'Connor, T.G. Previous prenatal loss as a predictor of perinatal depression and anxiety. Br. J. Psychiatry 2011, 198, 373-378. [CrossRef] [PubMed]

24. Heron, J.; O'Connor, T.G.; Evans, J.; Golding, J.; Glover, V. The course of anxiety and depression through pregnancy and the postpartum in a community sample. J. Affect. Disord. 2004, 80, 65-73. [CrossRef] [PubMed]

25. Collin, S.M.; Tilling, K.; Joinson, C.; Rimes, K.A.; Pearson, R.M.; Hughes, R.A.; Sterne, J.A.; Crawley, E. Maternal and childhood psychological factors predict chronic disabling fatigue at age 13 years. J. Adolesc. Health 2015, 56, 181-187. [CrossRef]

26. Glover, V.; O'Connor, T.G.; Heron, J.; Golding, J. Antenatal maternal anxiety is linked with atypical handedness in the child. Early Hum. Dev. 2004, 79, 107-118. [CrossRef] [PubMed]

27. Wiles, N.J.; Peters, T.J.; Heron, J.; Gunnell, D.; Emond, A.; Lewis, G. Fetal growth and childhood behavioral problems: Results from the ALSPAC cohort. Am. J. Epidemiol. 2006, 163, 829-837. [CrossRef] [PubMed]

28. Capron, L.E.; Glover, V.; Pearson, R.M.; Evans, J.; O'Connor, T.G.; Stein, A.; Murphy, S.E.; Ramchandani, P.G. Associations of maternal and paternal antenatal mood with offspring anxiety disorder at age 18 years. J. Affect. Disord. 2015, 187, 20-26. [CrossRef] [PubMed]

29. National Institute for Health and Care Excellence (NICE). Antenatal and Postnatal Mental Health: Clinical Management and Service Guidance; Clinical Guideline 192; NICE: London, UK, 2014. Available online: http://www.nice.org.uk/guidance/cg192 (accessed on 19 April 2021).

30. Ramchandani, P.G.; Hotopf, M.; Sandhu, B.; Stein, A. The epidemiology of recurrent abdominal pain from 2 to 6 years of age: Results of a large, population-based study. Pediatrics 2005, 116, 46-50. [CrossRef] [PubMed]

31. Patel, V.; Rodrigues, M.; DeSouza, N. Gender, poverty, and postnatal depression: A study of mothers in Goa, India. Am. J. Psychiatry 2002, 159, 43-47. [CrossRef] [PubMed]

32. Boyd, A.; Golding, J.; Macleod, J.; Lawlor, D.A.; Fraser, A.; Henderson, J.; Molloy, L.; Ness, A.; Ring, S.; Davey Smith, G. Cohort Profile: The 'children of the 90s' - the index offspring of the Avon Longitudinal Study of Parents and Children. Int. J. Epidemiol. 2013, 42, 111-127. [CrossRef]

33. Fraser, A.; Macdonald-Wallis, C.; Tilling, K.; Boyd, A.; Golding, J.; Davey Smith, G.; Henderson, J.; Macleod, J.; Molloy, L.; Ness, A.; et al. Cohort Profile: The Avon Longitudinal Study of Parents and Children: ALSPAC mothers cohort. Int. J. Epidemiol. 2013, 42, 97-110. [CrossRef] [PubMed]

34. University of Bristol. Explore Data and Samples. Available online: http://www.bristol.ac.uk/alspac/researchers/our-data/ (accessed on 16 August 2020).

35. ud Din, Z.; Emmett, P.; Steer, C.; Emond, A. Growth outcomes of weight faltering in infancy in ALSPAC. Pediatrics 2013, 131, e843-e849. [CrossRef] [PubMed]

36. Clegg, J.; Law, J.; Rush, R.; Peters, T.J.; Roulstone, S. The contribution of early language development to children's emotional and behavioural functioning at 6 years: An analysis of data from the Children in Focus sample from the ALSPAC birth cohort. J. Child Psychol. Psychiatry 2015, 56, 67-75. [CrossRef]

37. Taylor, C.M.; Kordas, K.; Golding, J.; Emond, A.M. Data relating to prenatal lead exposure and child IQ at 4 and 8 years old in the Avon Longitudinal Study of Parents and Children. Neurotoxicology 2017, 62, 224-230. [CrossRef]

38. Ford, E.; Shakespeare, J.; Elias, F.; Ayers, S. Recognition and management of perinatal depression and anxiety by general practitioners: A systematic review. Fam. Pract. 2017, 34, 11-19. [CrossRef]

39. O'Hara, M.W.; Wisner, K.L. Perinatal mental illness: Definition, description and aetiology. Best Pract. Res. Clin. Obstet. Gynaecol. 2014, 28, 3-12. [CrossRef] [PubMed]

40. Northstone, K.; Emmett, P.; Nethersole, F.; Alspac Study Team Avon Longitudinal Study of Pregnancy Childhood. The effect of age of introduction to lumpy solids on foods eaten and reported feeding difficulties at 6 and 15 months. J. Hum. Nutr. Diet. 2001, 14, 43-54. [CrossRef] [PubMed]

41. Emmett, P.M.; Hays, N.P.; Taylor, C.M. Antecedents of picky eating behaviour in young children. Appetite 2018, 130, 163-173. [CrossRef]

42. Ertel, K.A.; Koenen, K.C.; Rich-Edwards, J.W.; Gillman, M.W. Antenatal and postpartum depressive symptoms are differentially associated with early childhood weight and adiposity. Paediatr. Perinat. Epidemiol. 2010, 24, 179-189. [CrossRef] [PubMed]

43. Kidger, J.; Heron, J.; Lewis, G.; Evans, J.; Gunnell, D. Adolescent self-harm and suicidal thoughts in the ALSPAC cohort: A self-report survey in England. BMC Psychiatry 2012, 12, 69. [CrossRef] [PubMed]

44. Odd, D.; Evans, D.; Emond, A. Preterm Birth, Age at School Entry and Long Term Educational Achievement. PLoS ONE 2016, 11, e0155157. [CrossRef]

45. Freeman, J.V.; Cole, T.J.; Chinn, S.; Jones, P.R.; White, E.M.; Preece, M.A. Cross sectional stature and weight reference curves for the UK, 1990. Arch. Dis. Child. 1995, 73, 17-24. [CrossRef] 
46. Drewett, R.; Blair, P.; Emmett, P.; Emond, A. Failure to thrive in the term and preterm infants of mothers depressed in the postnatal period: A population-based birth cohort study. J. Child Psychol. Psychiatry 2004, 45, 359-366. [CrossRef] [PubMed]

47. Carey, V.J.; Lumley, T.; Ripley, B. Gee: Generalized Estimation Equation Solver, Version 4.13-19. Available online: http://CRAN. R-project.org/package= gee (accessed on 28 September 2021).

48. van Buuren, S.; Groothuis-Oudshoorn, K. mice: Multivariate Imputation by Chained Equations in R. J. Stat. Softw. 2011, 45, 1-67. [CrossRef]

49. Rubin, D.B. Multiple Imputation for Nonresponse in Surveys; John Wiley \& Sons: New York, NY, USA, 1987.

50. Johnson, J.; Stewart, D.E. DSM-V: Toward a gender sensitive approach to psychiatric diagnosis. Arch. Women's Ment. Health 2010, 13, 17-19. [CrossRef]

51. Edhborg, M.; Carlberg, M.; Simon, F.; Lindberg, L. “Waiting for Better Times": Experiences in the First Postpartum Year by Swedish Fathers With Depressive Symptoms. Am. J. Men's Health 2015, 10, 428-439. [CrossRef] [PubMed]

52. Darwin, Z.; Galdas, P.; Hinchliff, S.; Littlewood, E.; McMillan, D.; McGowan, L.; Gilbody, S. Fathers' views and experiences of their own mental health during pregnancy and the first postnatal year: A qualitative interview study of men participating in the UK Born and Bred in Yorkshire (BaBY) cohort. BMC Pregnancy Childb. 2017, 17, 45. [CrossRef] [PubMed]

53. O'Brien, A.P.; McNeil, K.A.; Fletcher, R.; Conrad, A.; Wilson, A.J.; Jones, D.; Chan, S.W. New Fathers' Perinatal Depression and Anxiety-Treatment Options: An Integrative Review. Am. J. Men's Health 2017, 11, 863-876. [CrossRef]

54. Ramchandani, P.; Psychogiou, L. Paternal psychiatric disorders and children's psychosocial development. Lancet 2009, 374, 646-653. [CrossRef]

55. World Health Organization. Infant and Young Child Feeding: Model Chapter for Textbooks for Medical Students and Allied Health Professionals; World Health Organization: Geneva, Switzerland, 2009.

56. Nanri, H.; Shirasawa, T.; Ochiai, H.; Nomoto, S.; Hoshino, H.; Kokaze, A. Rapid weight gain during infancy and early childhood is related to higher anthropometric measurements in preadolescence. Child Care Health Dev. 2017, 43, 435-440. [CrossRef] [PubMed]

57. Ong, K.K.; Ahmed, M.L.; Emmett, P.M.; Preece, M.A.; Dunger, D.B. Association between postnatal catch-up growth and obesity in childhood: Prospective cohort study. BMJ 2000, 320, 967-971. [CrossRef] [PubMed]

58. Ong, K.K.; Loos, R.J. Rapid infancy weight gain and subsequent obesity: Systematic reviews and hopeful suggestions. Acta Paediatr. 2006, 95, 904-908. [CrossRef] [PubMed]

59. Rafferty, J.; Mattson, G.; Earls, M.F.; Yogman, M.W.; Committee On Psychosocial Aspects Of Child And Family Health. Incorporating Recognition and Management of Perinatal Depression Into Pediatric Practice. Pediatrics 2019, 143, e20183260. [CrossRef]

60. Cox, J.L.; Holden, J.M.; Sagovsky, R. Detection of postnatal depression. Development of the 10-item Edinburgh Postnatal Depression Scale. Br. J. Psychiatry 1987, 150, 782-786. [CrossRef]

61. Felitti, V.J.; Anda, R.F.; Nordenberg, D.; Williamson, D.F.; Spitz, A.M.; Edwards, V.; Koss, M.P.; Marks, J.S. Relationship of childhood abuse and household dysfunction to many of the leading causes of death in adults. The Adverse Childhood Experiences (ACE) Study. Am. J. Prev. Med. 1998, 14, 245-258. [CrossRef]

62. de Barse, L.M.; Cardona Cano, S.; Jansen, P.W.; Jaddoe, V.V.W.; Verhulst, F.C.; Franco, O.H.; Tiemeier, H.; Tharner, A. Are parents' anxiety and depression related to child fussy eating? Arch. Dis. Child. 2016, 101, 533-538. [CrossRef]

63. Sin, J.; Galeazzi, G.; McGregor, E.; Collom, J.; Taylor, A.; Barrett, B.; Lawrence, V.; Henderson, C. Digital Interventions for Screening and Treating Common Mental Disorders or Symptoms of Common Mental Illness in Adults: Systematic Review and Meta-analysis. J. Med. Internet Res. 2020, 22, e20581. [CrossRef]

64. Philpott, L.F.; Savage, E.; FitzGerald, S.; Leahy-Warren, P. Anxiety in fathers in the perinatal period: A systematic review. Midwifery 2019, 76, 54-101. [CrossRef] 